Cahiers $d u$ MONDE RUSSE

\section{Cahiers du monde russe}

Russie - Empire russe - Union soviétique et États indépendants

$43 / 4 \mid 2002$

Intellectuels et intelligentsia

\title{
Corinna Kuhr-Korolev, Stefan Plaggenborg, Monica Wellmann, eds, Sowjetjugend 1917-1941
}

\section{Dorena Caroli}

\section{(2) OpenEdition}

\section{Journals}

Édition électronique

URL : https://journals.openedition.org/monderusse/4025

DOI : $10.4000 /$ monderusse. 4025

ISSN : $1777-5388$

\section{Éditeur}

Éditions de l'EHESS

\section{Édition imprimée}

Date de publication : 30 décembre 2002

Pagination : 715-716

ISBN : 2-7132-1796-2

ISSN : $1252-6576$

Référence électronique

Dorena Caroli, « Corinna Kuhr-Korolev, Stefan Plaggenborg, Monica Wellmann, eds, Sowjetjugend

1917-1941 », Cahiers du monde russe [En ligne], 43/4 | 2002, mis en ligne le 17 juin 2009, consulté le 03 septembre 2022. URL : http://journals.openedition.org/monderusse/4025 ; DOl : https://doi.org/ 10.4000/monderusse.4025

Ce document a été généré automatiquement le 3 septembre 2022.

Tous droits réservés 


\title{
Corinna Kuhr-Korolev, Stefan Plaggenborg, Monica Wellmann, eds, Sowjetjugend 1917-1941
}

\author{
Dorena Caroli
}

\section{RÉFÉRENCE}

Corinna KUHR-KOROLEV, Stefan PLAGGENBORG, Monica WELLMANN, eds,

Sowjetjugend 1917-1941. Generation zwischen Revolution und Resignation. Essen, Klartext, 2001, 310 p.

1 L'ouvrage collectif édité par Corinna Kuhr-Korolev, Stefan Plaggenborg et Monica Wellmann est constitué de douze articles traitant des pratiques violentes exercées et subies par la jeune génération soviétique, davantage marquée par l'expérience des guerres, mondiale et civile, de la révolution et du désarroi économique, que les autres générations européennes. Encadré de deux essais (introductif et conclusif) présentant des réflexions théoriques et méthodologiques sur les concepts de jeunesse et de violence dans l'URSS de l'entre-deux-guerres (1917-1941), ce recueil se propose de mettre en relation les expériences de la violence avec le Lebenswelt, c'est-à-dire le milieu social, de leurs " acteurs historiques". Thème central pour comprendre la société post-révolutionnaire et les processus de développement du stalinisme, le rapport des jeunes à la violence révèle les aspects contradictoires d'un groupe très hétérogène, tant par les expériences vécues que par l'âge, l'origine sociale et/ou la réception des idées révolutionnaires.

L'essai introductif explique pourquoi les bolcheviks n'ont étendu que de façon très limitée leur pouvoir (et/ou la culture prolétarienne) sur 20 millions de jeunes âgés de 15 à 24 ans (d'après un recensement effectué en 1926). Il montre aussi la réaction de la propagande du parti face à cette hétérogénéité de la population juvénile pendant la NEP ainsi que le degré d'assimilation de la culture communiste par la jeunesse. C. Kuhr- 
Korolev souligne la difficulté d'analyse de ces attitudes contradictoires chez les jeunes dont la vie privée devint de plus en plus la cible du parti à partir de 1926-1927. Ces facettes multiples du comportement de la jeunesse, à la fois attirée par le «charme discret » du mouvement de la jeunesse communiste (komsomol) et par les « subcultures » non officielles, persistent aussi pendant la première phase du stalinisme, lorsqu'une partie d'entre elle sera stigmatisée comme "ennemis de classe", tandis qu'une autre participera non seulement à la collectivisation mais aussi aux répressions violentes menées par le commissariat du peuple aux Affaires intérieures (NKVD). À la base de ces essais se trouve l'idée que le comportement violent des jeunes s'exprime tant par des actions à caractère antiétatique que par la destruction de soi-même et le hooliganisme. À partir de l'étude de l'historiographie allemande, H. Haumann souligne la spécificité des sentiments d'une génération issue de la Première Guerre mondiale. L'auteur s'interroge sur les causes multiples de la violence et ouvre des pistes de recherche intéressantes dans ce domaine.

3 Les deux premiers articles analysent d'abord l'attitude de criminalisation des comportements déviants de la jeunesse introduite par le stalinisme ainsi que la participation des jeunes aux répressions menées par le NKVD en 1936-1938 (G. Rittersporn), puis les phénomènes de violence physique et psychologique survenus à l'intérieur des écoles (parmi les élèves, ou entre élèves et enseignants), ainsi que les mécanismes de discrimination sociale mis en œuvre au début de la période stalinienne (S. Zhuravlev). Dans les deux articles suivants, M. Wellmann et V. Spiertz présentent deux études très approfondies concernant le suicide des jeunes membres de la jeunesse communiste et de l'Armée rouge, par le biais des sources officielles et des "lettres d'adieux » rédigées par les jeunes eux-mêmes. Ces « ego-documents » particulièrement précieux éclairent de façon très riche la vie quotidienne des jeunes étudiants et soldats ainsi que leur sentiment face à l'avenir. V. Isaev et D. Tchudi décrivent les pratiques violentes des jeunes dans le contexte de la militarisation de la jeunesse entamée en Sibérie à partir de 1927 et du processus d'implantation du nouvel ordre révolutionnaire bolchevik à Smolensk (1918-1919). Le contraste entre la société d'Ancien Régime et celle qui émerge avec la Russie soviétique, ainsi que les conflits entre ancienne et nouvelle génération, sont décrits par A. Rozhkov, I. Tirado et M. Shkarovskij à partir de l'étude de la société cosaque du Kuban, des campagnes soviétiques et de l'adhésion aux associations religieuses. Enfin, les articles de A. Gorsuch et de C. Kuhr-Korolev montrent comment la jeunesse échappait à ces projets de culture communiste proposée par le pouvoir tant dans son comportement public - politique - que dans sa vie privée (y compris sexuelle).

Ce livre, qui représente sans aucun doute un jalon important pour l'étude de l'histoire de la jeunesse en URSS, constitue un ouvrage novateur aussi bien du point de vue méthodologique que de celui des sujets traités. Ainsi il a recours à de nouvelles stratégies d'analyse du quotidien soviétique de l'entre-deux-guerres pour jeter un éclairage nouveau sur le mouvement de la jeunesse communiste, sur les comportements conformes et déviants, les conflits de générations, les formes de gouvernement des nouveaux groupes sociaux prolétaires et paysans. En outre, l'hypothèse de S. Plaggenborg selon laquelle « la jeunesse soviétique n'existait pas à l'extérieur d'un espace dépourvu d'État» (p.302), soutenue par l'argument qu'elle constitue "une construction culturelle » difficile à cerner dans les sources soviétiques des années 1920, révèle un des aspects les plus intéressants et contradictoires de la politique des bolcheviks et du parti communiste à l'égard de la jeunesse. 
5 Cependant la « réduction de l'espace » consacré à la nouvelle génération n'a pas été, à nos yeux, déterminée exclusivement par « une construction culturelle ", mais aussi par l'absence d'une véritable politique sociale garantissant une intégration dans la société à la nouvelle génération, frappée tant par le chômage que par un accès trop réduit à l'école. C'est dans ce contexte qu'on pourrait voir l'un des paradoxes les plus forts des politiques publiques des années 1920, c'est-à-dire le fait de vouloir assimiler une génération hétérogène sans que l'État s'investisse dans la mise en œuvre de politiques culturelle et sociale. C'est pourquoi cette carence invite à réfléchir davantage, aussi bien sur le rôle de la nouvelle génération dans différentes sociétés marquées par des crises économiques importantes que sur les effets psychologiques et émotionnels générés par ces crises sur cette tranche d'âge en ce qui concerne la construction de son identité. 